side, was, at a prearranged moment, demolished by blasting, allowing the unbalanced obelisk to roll forward over the cylindrical surface of the remaining pedestal and fall prone into the torrent, in this way completely arresting in a few seconds a volume of nearly 2000 cubic feet of water racing at a velocity of about $30 \mathrm{ft}$. per sec. A view of the incident is given in Fig. 2.

An operation of so unprecedented a character involved certain intricate problems, the calculated solutions of which were checked by the construction of a model to a scale of $1 / 50$ in the Hydraulic Laboratory of the Carnegie Institute of Technology, Pittsburgh. Recording devices on the model gave practical demonstration of the effect of the water cushion on the impact, and of the dynamic stroke of the stream against the obelisk before reaching the bed. It is satisfactory to learn that the whole operation of overturning the huge mass was carried through without a hitch of any kind. After the explosion of the charge of dynamite, the obelisk fell exactly in accordance with the calculations, and landed on the river bed within an inch of its destined position. The impact recorders showed that almost the whole (99.6 per cent) of the energy of the falling mass was absorbed by the cushion provided by the water.

1 Hydro-electric Progress in Canada in 1931; Report No. 1571. Water Power Resources of Canada; Report No. 1573. 2 NATURE, July 27, 1929.

\title{
The Hereditary Transmission of Acquired Characters *
}

\author{
By Prof. J. B. S. Haldane, F.R.S.
}

$\mathrm{I}^{\mathrm{N}}$ another series of experiments which MacBride quotes, Harrison induced a race of the willow gallfly, Pontania salicis, to change its food plant from one species of willow to another. He first showed that a race taken from Salix phylicifolia, when given the choice of 21 species or subspecies of willow, confined themselves almost wholly to the original plant and to the related Salix Andersoniana. However, in addition, 3.5 per cent of the eggs were laid on Salix rubra. In two out of three years the galls on this latter plant failed. In one year seven of them reached maturity. In a second experiment, Harrison let loose gallflies from Salix Andersoniana in a patch of willows consisting entirely of Salix rubra. The eggs were perforce laid on the latter, and the large majority of the galls aborted in the first two years, but fewer in the next two. At the end of the fourth year, Salix Andersoniana was planted near the patch, but in the course of two years no galls were formed on it.

There can be no question of the importance of Harrison's demonstration that a race of insects can in this way acquire a new character. But the reasons for this event are not so clear. Wheeler (who as a Lamarckian cannot be accused of bias) regards the choice of food in which to lay eggs as determined largely by memory of larval surroundings, and particularly smells. The other factor in successful colonisation is the ability of the larva to eat and digest its food. Now, as in the first years most of the galls aborted, it would seem likely that the larvæ were being very stringently selected. The capacity to grow on Salix rubra is rare in the original race. Only in 7 out of 57 galls on it did the larvæ mature. Until a definite proof of Lamarckian inheritance has been given, in any case, we are justified in putting down the observed facts to selection, perhaps aided by individual (not racial) memory. We know that variation occurs in man with regard to idiosyncrasy to foodstuffs, and there is evidence that it is inherited; the same is very probably true of insects.

* Continued from p. 819.
Finally, MacBride cites Metalnikoff's experiments on the acquired immunity of the moth Galleria mellonella to a bacillus. I quote one sentence from MacBride's account: "Affter three or four days the survivors were counted and allowed to develop and become the parents of the next generation ". Unless Galleria, unlike men, mice, and other species investigated, does not possess any innate variability in its resistance to disease, there has clearly been stringent selection, and we need not be surprised that a relatively resistant race has been developed.

I pass over several other cases where apparently Lamarckian effects have been due to infection, and Kammerer's experiments, which terminated in his suicide, to the very remarkable results obtained by McDougall on rats. Unlike the other workers here cited, he began with an approximately pure line of rats which had been inbred for many generations. He also took considerable precautions to avoid selection. Unfortunately, the procedure of training was twice changed during the experiment, so I shall only describe the latter half.

The rats at an age between three and four weeks were dropped into a tank of water in which two turnings led to platforms covered with wire gauze by which they could emerge. One of these (alternately on the right and left) was illuminated, and a rat stepping out of the water on to it received an electric shock. Each rat was dropped in six times daily until it learned to avoid the illuminated platform. Learning was regarded as complete when this occurred on twelve successive trials. After twelve generations, all but one of which had been trained under slightly different conditions, but had shown a decided increase in educability, the procedure was finally standardised. In nine generations the average number of errors fell from 80 to 25 , and the number made by the best rat from 42 to 3 . In an experiment on a related group, the number of errors fell from about 170 in the first generation to 114 in the fifth. Finally, the worst performers were selected during two generations, but in spite of this, the time needed for training fell. 
To obviate the possibility of tradition, mothers of a slightly trained stock were mated first with slow-learning and then with quick-learning males. The first mating gave an average number of 166 errors, the second of 62 . The character acquired appears to be caution. It does not seem to be general intelligence, general timidity, or a specific fear of the bright gangway.

One very important point which emerged was that the progeny of the trained rats at first showed much greater variation in learning power than those of the untrained. If capacity for learning is inherited within the group (which could be ascertained or disproved from McDougall's records were they published in full), the process of change would have been greatly accelerated if selection had also taken place, if in fact the spread of acquired variations through the population had been aided by selection, as Darwin thought was the case in ordinary evolution.

Now, whileit is clear that McDougall's experiment is in a class by itself, it has been criticised by Sonneborn, among others. Sonneborn notes that the intensity of the shock varied considerably and was not measured, and that McDougall found that rats subjected to light shocks took nearly three times as long to learn as when the shocks were heavy. So a progressive increase in the shock intensity could account for McDougall's results. He further points out that, if the method of choosing two rats 'at random' from a litter was to take the first two available in a cage, this would tend to select rats of a particular psychological disposition. Various other criticisms can be made. Hence it would seem that, while one must admit that MoDougall has made out a prima facie case, a suspension of judg. ment is not unreasonable before we regard him as having demonstrated a principle in evolution which is unsupported by other evidence of the same calibre. It is, moreover, worth noting that in another experiment, broken off after four generations, MeDougall found that the time needed for training increased in successive generations. He put this down to an increase in timidity, thus contriving to eat his cake and have it.

If we reject Lamarckism, we are, I think, left in the position termed neo-Darwinian, but concisely stated by Lucretius, one of the greatest minds of all history, two thousand years ago (I owe the quotation to Dr. C. D. Darlington).* Genes, the genitalia corpora of Lucretius, reproduce themselves at each cell division, and are handed down from parent to offspring. The genes in an organism determine how it will develop and behave in a given environment. The process of reproduction

\footnotetext{
* The quotation from Lamarck is a moderate statement of his doctrine. He sometimes stated it in an obviously false manner ; for example, in his "Histoire naturelle des animaux sans vertèbres" we read :

"Quatriéme loi. Tout ce qui a été acquis, tracé, ou changé dans l'organisation des individus, pendant le cours de leur vie, est conserve par la génération et tranamis aux nouveaux individus qui proviennent de ceux qui ont épreuvé ces changements."

For example, children acquire a full knowledge of their parents' language without education, and Jews are born circumcised I Lamarck's mistaken views on heredity do not, of course, lessen the greatness his work on evolution. But it is unfortunate that many French biologists tend to exalt Lamarck and neglect another great Frenchman, de vilmorin, whose discovery of pure lines laid the foundation of modern genetics.
}

No. 3267, Vor. 129]

of the gene is not perfect. Occasionally a gene produces another gene of a different type. This process is called mutation, and has never been shown to be adaptive, still less to perpetuate an acquired habit. Changes in the number of genes (for example, by doubling the chromosome number) also occur. Evolution is due to the fact that only a few of the possible combinations of genes survive. Were this not so, it would have been a mere orgy of variations without any particular trend.

I should like emphatically to protest against the view that the contest between Lamarckism and neo-Darwinism has anything to do with that between vitalism and mechanism. It would be quite possible to explain McDougall's results on thoroughly materialistic lines if the increased use by his rats of certain parts of the brain liberated specific substances into the blood, and these substances acted on the genes concerned with the elaboration of cerebral structure. Again, the neoDarwinian may be a thorough-going vitalist, regarding each gene as an elementary living thing, contributing to the communal life of the cell and the federal life of the organism. He differs from the Lamarckian in believing that the gene has a very high degree of autonomy. There is no more reason to describe him as a mechanist than to dub a man an anarchist if he thinks that Parliament should not reverse the decisions of the London County Council. Similarly, a Lamarckian can be a vitalist, and a Darwinian a mechanist; or, like myself, he may refuse to take either point of view.

Further, it is often stated that a refusal to admit that conscious purpose has played any important part in evolution is a gloomy and even immoral point of view. McDougall writes of "the Cimmerian darkness in which Neo-Darwinism finds itself ", and I admit that a theory which (like that of stellar structure) is largely based on integral equations is inevitably lacking in popular appeal. Nevertheless, the exact opposite seems to me to be the case. It has taken about a thousand million years for evolution to produce man, and the process has not only been slow but also often cruel. If mind had been an important evolutionary agent, there would be some ground for pessimism. If, on the other hand, it is only in our own time that the purposive guidance of the evolutionary process is becoming possible, then the outlook is altogether brighter. But if this is so, it is all the more our duty to examine as critically as possible the various evolutionary theories and to reject those which do not rest on a solid basis of observation.

From the human point of view the implications of the neo-Darwinian point of view were forcibly stated by the prophet Ezckiel (ch. 18, v. 2):

"What mean ye, that ye use this proverb concerning the land of Israel, saying, The fathers have eaten sour grapes, and the children's teeth are set on edge? As I live, saith the Lord God, ye shall not have occasion any more to use this proverb in Israel."

If we accept this point of view, each of us starts 
afresh with the genetical constitution derived from his or her parents. The way in which his ancestors have employed their talents is irrelevant. The slum child, if of sound constitution, will not be handicapped by the bad environment of his parents provided he is transplanted early enough. Nor, on the other hand, are the effects of university education inherited. By the process of death and reproduction the species throws off some of the intolerable burden of the past. Evolution is thus possible for the race at a rate and to an extent which would be impossible for the individual.

\section{Electrical Conductivity of Metals at the Lowest Temperature*}

W ITH the fairly large supplies of helium now available it is comparatively easy by the liquefaction of this gas to reach temperatures so low as $1^{\circ} \mathrm{K} .\left(-272^{\circ} \mathrm{C}\right.$. $)$. At this low temperature a few of the metals become perfect conductors of electricity. Most of them, however, still exhibit, when so cooled, a decreasingly small but still quite measurable resistance to the passage of a current.

In 1911, Kamerlingh Onnes at Leyden, while carrying out researches at low temperatures with the aid of liquefied helium, discovered that mercury, when cooled down and solidified with liquid helium, suddenly and abruptly at about $4 \cdot 2^{\circ} \mathrm{K}$. became what is now designated as a superconductor of electricity. At temperatures below $4 \cdot 2^{\circ} \mathrm{K}$. mercury offers no measurable resistance to the passage of a current. Currents of electricity started in a ring of mercury in the superconducting state will continue apparently undiminished in intensity while the metal is in that state. The duration of these persistent induced ring currents is limited only by the length of time the cooling agent, liquid helium, will last. Other metals that exhibit this superconducting property if made sufficiently cold are lead, tin, indium, gallium, thallium, tantalum, titanium, and niobium.

The transition temperature for the passing of a metal from the ordinary conducting to the superconducting state is not a constant but varies with the metal. For mercury it is $4 \cdot 2^{\circ} \mathrm{K}$., for lead $7.2^{\circ} \mathrm{K}$, tin $3.72^{\circ} \mathrm{K}$, tantalum $4.5^{\circ} \mathrm{K}$, thallium $2.39^{\circ} \mathrm{K}$, indium $3 \cdot 4^{\circ} \mathrm{K}$, gallium $1.07^{\circ} \mathrm{K}$, and niobium $8 \cdot 2^{\circ} \mathrm{K}$. Some alloys and chemical compounds of the metals also exhibit the superconducting phenomenon. Copper sulphide, for example, does so, though neither of the constituent elements is a superconductor. The nitrides and carbides, borides and silicides of several of the metals, such, for example, as molybdenum, tungsten, tantalum, zirconium, and niobium, are also superconducting at sufficiently low temperatures.

The addition of metals of the bismuth group to superconducting metals has been found, speaking generally, to raise their transition temperature. Bismuth added to lead raises the transition temperature from $7 \cdot 2^{\circ} \mathrm{K}$. to $8 \cdot 8^{\circ} \mathrm{K}$.; carbon raises that of niobium from $8 \cdot 2^{\circ} \mathrm{K}$. to $10 \cdot 5^{\circ} \mathrm{K}$. Gold alloyed with bismuth becomes superconducting at $1.94^{\circ} \mathrm{K}$., whereas neither constituent alone becomes superconducting even at the lowest temperatures obtainable.

The application of mechanical stresses such as

- Substance of the Friday evening discourse delivered by Prof. J. C MeLennan, F.R.S., at the Royal Institution on June 3. those of torsion and tension raise the transition temperature of a superconducting metal, but the application of a magnetic field delays the appearance of superconductivity in a metal, and causes it to appear at a lower temperature than normally.

If a metal in the superconducting state be subjected to a gradually increasing magnetic field, a critical field strength is reached when electrical resistance reappears in the metal. The strengths of the critical fields required for different superconductors vary; an alloy of bismuth and lead, for example, at $1 \cdot 2^{\circ} \mathrm{K}$. requires a magnetic field of 20,000 gauss to restore the property of electrical resistance, while metallic thallium at the same temperature requires a field of only $\mathbf{1 5}$ gauss.

Since the electrical resistance of superconducting metals is zero, no heat is produced when electrical currents are passed through them. Currents of high intensity can therefore be passed through superconducting wires of small diameter without melting them. Electric currents of more than 1000 amperes have been so obtained in wires of small cross-section. The factor that imposes a limiting value upon the current strength is the magnetic field set up in the wire by the current itself. A critical value is reached when resistance is restored to the wire by the magnetic field.

Interest in the problem of superconductivity in metals recently received a stimulus through the discovery by Prof. McLennan and his collaborators that the transition temperatures with alternating electric fields applied are not the same for superconducting metals as when direct currents are passed through them. In a series of experiments with a coil of tin wire, drawn to a diameter of $0.3 \mathrm{~mm}$., it was found that with direct currents the resistance of the coil began to decrease abruptly at $3.76^{\circ} \mathrm{K}$. and disappeared completely at $3.70^{\circ} \mathrm{K}$. Experiments with the same coil with currents of frequency $1 \cdot 1 \times 10^{7}$ per second gave for the corresponding temperatures $3.67^{\circ} \mathrm{K}$. and $3 \cdot 61^{\circ} \mathrm{K}$.; that is, superconductivity did not begin to appear until a temperature was reached that was below the one at which it was complete in the case of the direct current experiments. Further experiments with higher frequencies revealed depressions of the critical transition temperature, increasing in amount with the frequency. Extrapolation of the transition temperature-frequency curve, which appeared to be linear for the higher frequencies, gave $10^{9}$ per second for the frequency corresponding to $0^{\circ} \mathrm{K}$.

With tantalum wires, results were obtained similar in character to those found with wires of tin and of lead. Experiments with tin wire coils 